\title{
Our Journey Toward Becoming a High Impact Journal
}

The change in the name of our journal to Annals of Geriatric Medicine and Research (AGMR) in September 2016 marks the successful launch of a new beginning with AGMR. Outstanding review articles on key issues in geriatrics and original articles with high scientific quality have been published in AGMR. As a result of these efforts, since January 2018, our journal has been listed in the Directory of Open Access Journals (DOAJ), a comprehensive international database of open access journals. The inclusion in DOAJ is expected to raise international interest in our journal. In addition, our journal has been listed in Emerging Sources Citation Index database included within Web of Science of Clarivate Analytics since March 2018. Our journal is under evaluation for inclusion in the Scientific Citation Index Expanded journal list for the next 2-3 years. These achievements are attributable to dedicated efforts and commitment of the editorial board and editorial staff, and to the readers for their interest.

The next 2 years are crucial for our journal. In our endeavor of improving the scientific and editorial quality of the journal, we identified a few unaddressed issues in the editorial and publication processes of the journal. To resolve these issues and to develop as a highly qualified journal, we have started publishing with a new publication partner. We will strive to meet the high standard of the editorial process and work together toward achieving an irreproachable level. Furthermore, we have carefully reviewed the Principle of Transparency and Best Practice in Scholarly Publishing, Joint Statement by the Committee on Publication Ethics, the DOAJ, and other associations (http://doaj.org/bestpractice). ${ }^{1)}$ We determined all possible elements that did not comply with the Best Practice Guideline or were not clearly addressed in terms of edito- rial policy and ethics. For example, dealing with data indicating misconduct and handling complaints and appeals needed to be addressed more clearly on the journal webpage. Thus, potential problems that may reduce the editorial quality were identified and corrected one by one. We launched a new journal webpage (www.e-agmr.org) that reflects these developments. Meanwhile, we noted that some articles published in AGMR did not have statements on animal rights or informed consent in the main text. The authors were given the opportunity to amend these errors. The results or corrections will be noted as corrigenda in the upcoming issue.

As our journey toward becoming a high impact journal continues, I believe the scientific and editorial quality of articles published in AGMR will soon advance beyond the current standard of journal publication. I look forward to the day when I can include AGMR as one of the highimpact journals in Geriatrics and Gerontology.

Jae-Young Lim, MD, PhD Editor-in-Chief

https://orcid.org/0000-0002-9454-0344

Department of Rehabilitation Medicine, Seoul National University Bundang Hospital, Seoul National University College of Medicine, Seongnam, Korea E-mail: drlim1@snu.ac.kr

\section{REFERENCE}

1. Principles of Transparency and Best Practice in Scholarly Publishing [Internet]. Directory of Open Access Journal; 2018 Jan 15. [cited 2018 Jun 22]. Available from: https://doaj.org/bestpractice. 